\title{
Magnetic properties of surface soils across the southern Tarim Basin and their relationship with climate and source materials
}

\author{
ZAN JinBo ${ }^{1,2}$, FANG XiaoMin ${ }^{1,2^{*}}$, NIE JunSheng ${ }^{2}$, YANG ShengLi $^{3,1}$, SONG ChunHui $^{2}$ \& \\ DAI Shuang ${ }^{2}$ \\ ${ }^{1}$ Center for Basin Resource and Environment, Institute of Tibetan Plateau Research, Chinese Academy of Sciences, Beijing 100085, China; \\ ${ }^{2}$ Key Laboratory of Western China's Environmental Systems, Ministry of Education of China, Lanzhou 730000, China; \\ ${ }^{3}$ College of Geography Science, Nanjing Normal University, Nanjing 210046, China
}

Received May 4, 2010; accepted August 23, 2010

\begin{abstract}
The magnetic susceptibility $(\chi)$ of surface soils on the Chinese Loess Plateau (CLP) has strong positive correlation with mean annual precipitation. It is widely accepted that ultrafine magnetite/maghemite grains produced during pedogenesis are responsible for the enhancement of $\chi$, and loess $\chi$ on the CLP has been widely used as a proxy for the intensity of the East Asian summer monsoon. However, few works have investigated mechanisms for the enhancement of $\chi$ in the case of surface aeolian sediments in westerly-dominated inland China, north of the Tibetan Plateau. Here detailed rock magnetism and grain size studies of 49 surface samples taken across the southern Tarim Basin for different rainfall/temperature/altitude conditions are presented. The results show that samples taken from desert have the lowest $\chi$ values and that $\chi$ of loessic sand and loess samples decreases with increasing altitude. In addition, the rock magnetism studies suggest that the magnetic properties of surface soils across the southern Tarim Basin are mainly controlled by the concentration of coarse aeolian ferrimagnetic minerals. The contribution of ultrafine pedogenically produced magnetic grains to $\chi$ is very limited.
\end{abstract}

surface soils, magnetic susceptibility, grain size, Tarim Basin, rock magnetism

Citation: Zan J B, Fang X M, Nie J S, et al. Magnetic properties of surface soils across the southern Tarim Basin and their relationship with climate and source materials. Chinese Sci Bull, 2011, 56: 290-296, doi: 10.1007/s11434-010-4210-4

The loess-paleosol sequence and the underlying red-clay sequence on the Chinese Loess Plateau (CLP) are regarded as one of the best terrestrial paleoclimate archives of the late Cenozoic period. Variations in the magnetic susceptibility $(\chi)$ of surface soils on the CLP have strong positive correlation with mean annual precipitation, and ultrafine magnetite/maghemite grains produced during pedogenesis are considered to be mainly responsible for enhancements of $\chi$ [1-8]. Thus, the low-frequency $\chi$ of loess can be taken as a proxy for paleo-rainfall on the CLP [9-14].

In contrast, mechanisms for the magnetic enhancement for loess samples taken from outside the CLP are complicated. For example, higher $\chi$ during glacial periods and

*Corresponding author (email: fangxm@itpcas.ac.cn) lower $\chi$ during interglacial periods have been observed in the cases of Alaska loess and Siberia loess. The wind-vigor model [15-18] and pedogenic model [19,20] have been proposed to explain the complicated correlation. In addition, many studies have shown that coarse aeolian magnetic minerals also affect $\chi$, especially in the loess-paleosol sequence adjacent to the desert edge $[21,22]$. Thus, studies of the distribution characteristics and controlling factors of $\chi$ for surface soils having different climates and environments will greatly improve our understanding of the relationship between the climate and $\chi$.

Previous rock magnetism works have focused on the CLP, a region dominated by the East Asian monsoon. In contrast, few works have been done to clarify the enhancement mechanisms of $\chi$ for surface aeolian sediments in 
westerly-dominated inland China, north of the Tibetan Plateau. Aeolian sediments were deposited on varying geomorphic surfaces across the southern Tarim Basin [23], from 900 to $4500 \mathrm{~m}$ a.s.l. excluding 1400-2000 m a.s.l., where there are Gobi gravels. These aeolian deposits correspond to different rainfall and temperature conditions at different altitudes, allowing us to study the mechanisms of magnetic enhancement. Here we present a preliminary study on the rock magnetism and grain size of 49 surface samples taken across the southern Tarim Basin to pave the road for more detailed rock magnetism studies in the westerlydominated region.

\section{Samples and methods}

A total of 49 surface soil samples were collected at 20-100 $\mathrm{m}$ elevation intervals between 900 and $4500 \mathrm{~m}$ a.s.l. across the southern Tarim Basin (Figure 1). These samples cover three belts [23] (sand desert below $1400 \mathrm{~m}$ a.s.l., loessic sand at 2000-2500 $\mathrm{m}$ a.s.l. and loess at 2500-4500 $\mathrm{m}$ a.s.1.) and are from areas having different rainfall and temperature conditions [24]. A sample taken at a site was a mixture of the top $5 \mathrm{~cm}$ of the uncultivated soil profile far from industries and villages.

The grain sizes of samples were analyzed using a Microtrac S3500 laser particle sizer at the Institute of Tibetan Plateau Research, Chinese Academy of Sciences. First, we removed organic matter from the samples by boiling samples in $10 \% \mathrm{H}_{2} \mathrm{O}_{2}$ solution. We then removed carbonates from the samples by putting them in $10 \% \mathrm{HCl}$ solution. Finally, we put samples into $3.6 \%\left(\mathrm{NaPO}_{3}\right)_{6}$ solution and dispersed them in an ultrasonic bath for 10 minutes.

Magnetic susceptibility was measured using a Bartington MS2 susceptometer at frequencies of 470 and $4700 \mathrm{~Hz}$ (In this paper, $\chi$ is the low-frequency mass-specific magnetic susceptibility measured at $470 \mathrm{~Hz}$; i.e. $\left.\chi=\chi_{470 \mathrm{~Hz}}\right) \cdot \chi_{\mathrm{fd}}$ $\left(\chi_{470 \mathrm{~Hz}}-\chi_{4700 \mathrm{~Hz}}\right)$ and $\chi_{\mathrm{fd}} \%\left(\left(\chi_{470 \mathrm{~Hz}}-\chi_{4700 \mathrm{~Hz}}\right) / \chi_{470 \mathrm{~Hz}} \times 100 \%\right)$ were then calculated. The isothermal remanent magnetization
(IRM) and saturation isothermal remanent magnetization $\left(\mathrm{SIRM}=\mathrm{IRM}_{1000 \mathrm{mT}}\right)$ were obtained employing an ASC pulse magnetizer and Molspin Minispin magnetometer. Backward IRM was then imparted at $0.3 \mathrm{~T}$ after reversing the orientation of the samples. Hysteresis loops and magnetization versus temperature curves were obtained employing the variable field transition balance. All these measurements were performed at the National Laboratory of Western China's Environmental Systems of the Ministry of Education of China, Lanzhou University.

\section{Results}

\section{$2.1 \chi$, SIRM and grain size}

$\chi$ of surface soils across the southern Tarim Basin is generally low and ranges between 1.5 and $4.0 \times 10^{-7} \mathrm{~m}^{3} / \mathrm{kg}$ (Figure 2). In the desert, $\chi$ is generally less variable and has the lowest values $\left(1.5 \times 10^{-7} \mathrm{~m}^{3} / \mathrm{kg}\right.$ on average $)$, but in loessic sand and loess belts, $\chi$ is higher and has an obvious negative linear correlation $\left(R^{2}=0.78\right)$ with altitude (Figure $\left.3(\mathrm{~b})\right)$. In addition, $\chi_{\mathrm{fd}}$ and $\chi_{\mathrm{fd}} \%$ are lower and less variable for all the samples and there are no obvious correlations between $\chi_{\mathrm{fd}}$ or $\chi_{\mathrm{fd}} \%$ and $\chi$ (Figure 2 ).

$\chi$ values of more than 160 surface soils in China were recorded by Lü et al. to assess the relationship between $\chi$ and modern climatic parameters and they found that there was no obvious relationship between $\chi$ and the mean annual temperature or mean annual precipitation for surface soils across the southern Tarim Basin [9]. This indicates that pedogenically produced ultrafine ferrimagnetic minerals do not play a dominant role in determining $\chi$ in this area. The weak correlation between $\chi$ and $\chi_{\mathrm{fd}}$ or $\chi_{\mathrm{fd}} \%$ for surface soils across the southern Tarim Basin further supports this hypothesis.

SIRM is largely controlled by ferrimagnetic and canted antiferromagnetic minerals, without the influence of paramagnetic and diamagnetic materials [25,26]. Figure 2

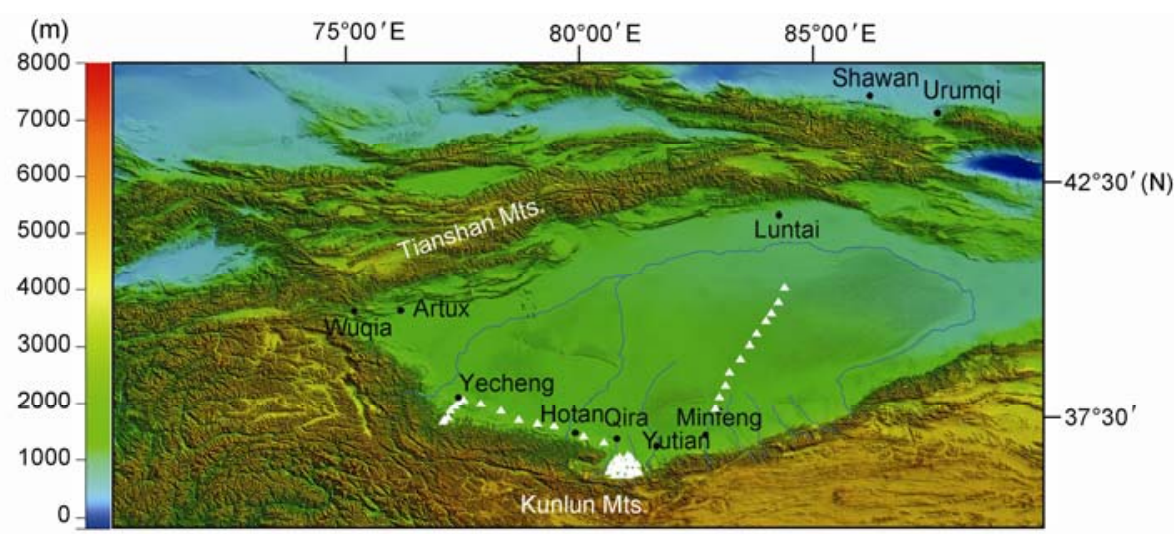

Figure 1 DEM map of the Tarim Basin and sampling locations (triangles). 


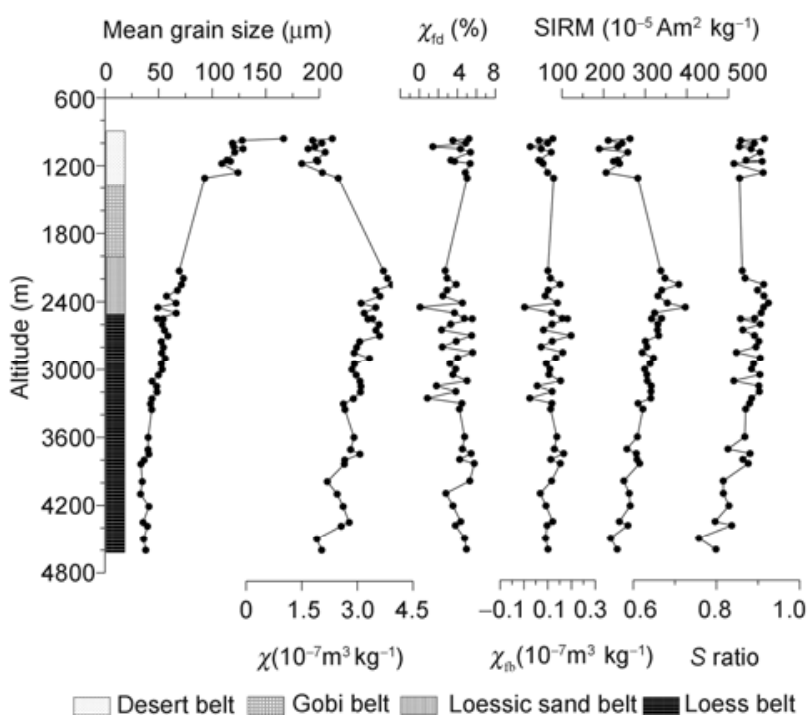

Figure 2 Lithology, mean grain size and magnetic parameter records for surface soils across the southern Tarim Basin.

shows that the SIRM curve roughly duplicates the $\chi$ curve. Samples from the desert have the least SIRM, and SIRM of loessic sand and loess samples decreased with increasing altitude, which further supports the systematic variations in magnetic properties for different deposit belts and altitudes as suggested by the $\chi$ values.

A total of 49 samples collected from the surface soils of the southern Tarim Basin give a general picture of the grain-size distribution (Figure 2). Samples in the desert zone contain a higher percentage of coarser materials and the mean grain size (MZ) is generally greater than $100 \mu \mathrm{m}$. Loessic sand and loess samples consist mainly of silt and very fine sand with $\mathrm{MZ}$ ranging from 30 to $70 \mu \mathrm{m}$. Correlation analysis indicates that $\mathrm{MZ}$ and altitude have a strong negative correlation $\left(R^{2}=0.96\right)$ for all surface soils samples (Figure 3(a)). In addition, in contrast to the weak correlation between $\chi$ and $\chi_{\mathrm{fd}}$ or $\chi_{\mathrm{fd}} \%$ (Figure 2), MZ and $\chi$ have a similar trend with increasing altitude (Figures 2 and 3 ) for loessic sand and loess samples, indicating that variations in aeolian materials due to wind sorting possibly control the magnetic properties of surface samples taken from loessic sand and loess.

\subsection{Temperature dependence of saturation magnetization}

Magnetization variations with temperature not only indicate the magnetic mineral type but also reveal the change in magnetic mineralogy during heating and cooling [26]. The Ms ( $\mathrm{T}$ ) curves show that all samples have a rapid loss of magnetization near $580^{\circ} \mathrm{C}$ and that the magnetization of samples taken from the desert zone drops to zero (Figure 4), indicating magnetite is the dominant mineral in these samples. According to the different characteristics of the Ms (T) curves (Figure 4), samples can be divided into three categories: (1) desert samples, for which the magnetization in the cooling curve is slightly greater than that in the heating curve, implying that weakly magnetic materials, such as iron sulfides or other paramagnetic minerals, are converted to strongly magnetic magnetite as a result of oxidation during heating $[19,20],(2)$ loessic sand and loess samples between 2100 and $3300 \mathrm{~m}$, for which the magnetization in the cooling curve is less than that in the heating curve, which is probably due to thermally unstable maghemite minerals converting to hematite, resulting in a loss of magnetization $[19,20]$, and (3) loess samples above $3300 \mathrm{~m}$, for which the magnetization in the cooling curve is much greater (more than double) than that in the heating curve and all heating curves have a clear "hump" at around $500^{\circ} \mathrm{C}$. These observations indicate that the types and contents of weakly magnetic minerals differ greatly from those of desert samples [20].

\subsection{Hysteresis parameters}

The shapes of magnetic hysteresis loops are useful indicators of the grain size and type of magnetic mineral [25]. Hysteresis loops for all the samples are narrow at the center and the loops are closed by a field of $300 \mathrm{mT}$ (Figure 5), implying a soft (more easily saturated) magnetic component,
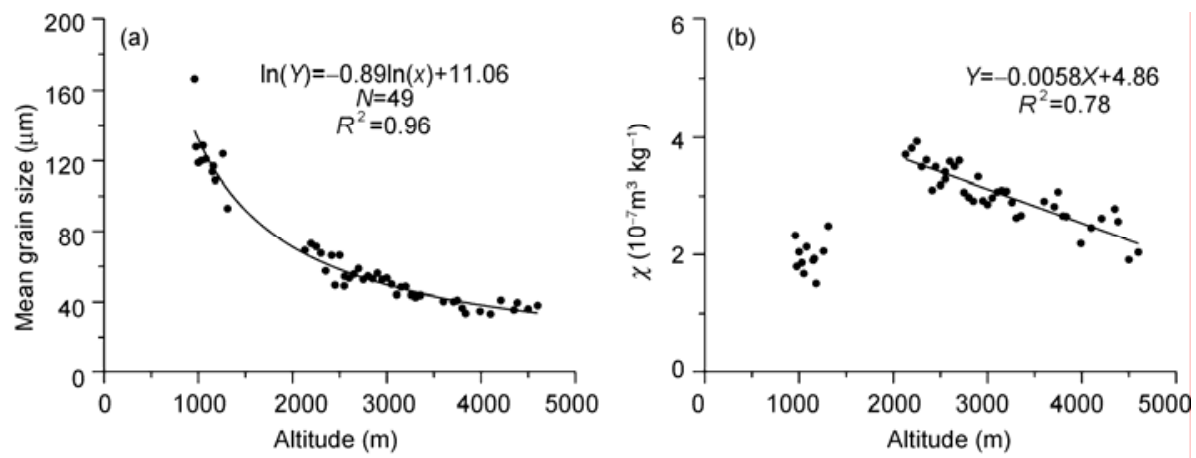

Figure 3 Correlation between mean grain size and altitude (a) and $\chi$ and altitude (b) for surface aeolian sediments across the southern Tarim Basin. 

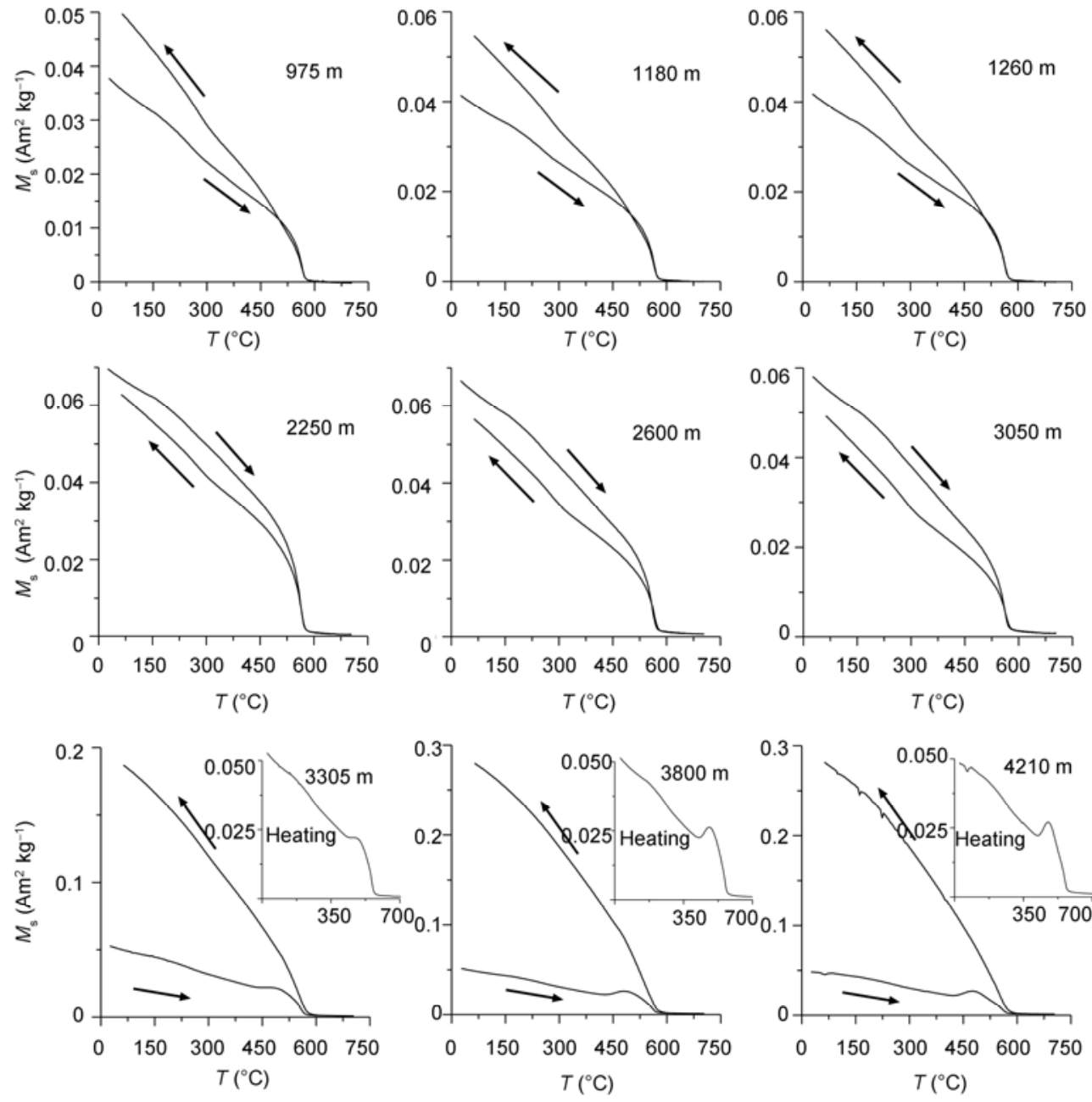

Figure 4 Thermomagnetic curves for surface aeolian sediments across the southern Tarim Basin.

such as maghemite and/or magnetite, is the major carrier of magnetic remanence.

\subsection{IRM and $S$ ratio}

Acquisition of IRM and its back-field demagnetization is an important magnetic method for identifying the magnetic composition [27]. Stepwise acquisition of the isothermal remanent magnetization in a field up to $2500 \mathrm{mT}$ shows that more than $90 \%$ of the SIRM was acquired in a field of 300 mT for most surface samples (Figure 6a), suggesting that magnetic properties of the surface aeolian sediments across the southern Tarim Basin are dominated by low-coercivity ferrimagnetic minerals; i.e. magnetite or maghemite. However, loessic sand and loess samples do not become fully saturated even with an applied field of $2500 \mathrm{mT}$ (Figure 6(a)), reflecting the existence of hard magnetic minerals.

Progressive removal of SIRM by applying reversed fields reveals that desert samples have the lowest values of remanent coercivity (40-45 mT) and SIRM (Figure 6(b)), suggesting that although low-coercivity ferrimagnetic minerals are the major carrier of magnetic remanence in desert samples, the content is not high. In addition, in contrast to the decrease in SIRM, the remanent coercivities of loessic sand and loess samples increase with altitude $(50 \mathrm{mT}$ between 2100 and $3300 \mathrm{~m}$ and $55 \mathrm{mT}$ above $3300 \mathrm{~m}$ ) (Figure 6(b)), indicating a greater concentration of high-coercivity magnetic minerals in the samples above $3300 \mathrm{~m}$.

The $S$ ratio $\left(-\mathrm{IRM}_{-300 \mathrm{mT}} / \mathrm{SIRM}\right)$ further supports the above hypothesis (Figure 2). The $\mathrm{S}$ ratio serves as a measure of the relative content of low-coercivity components, and samples having a greater low-coercivity component will have a higher $S$ ratio [26]. The decrease in the $S$ ratio with increasing altitude shows that samples taken from loessic sand and loess belts at higher altitude have a greater concentration of high-coercivity magnetic minerals. In the desert, however, all samples with a high $S$ ratio have low $\chi$ and SIRM, suggesting that although magnetic properties of the desert samples are dominated by soft magnetic components, the content is not high. 

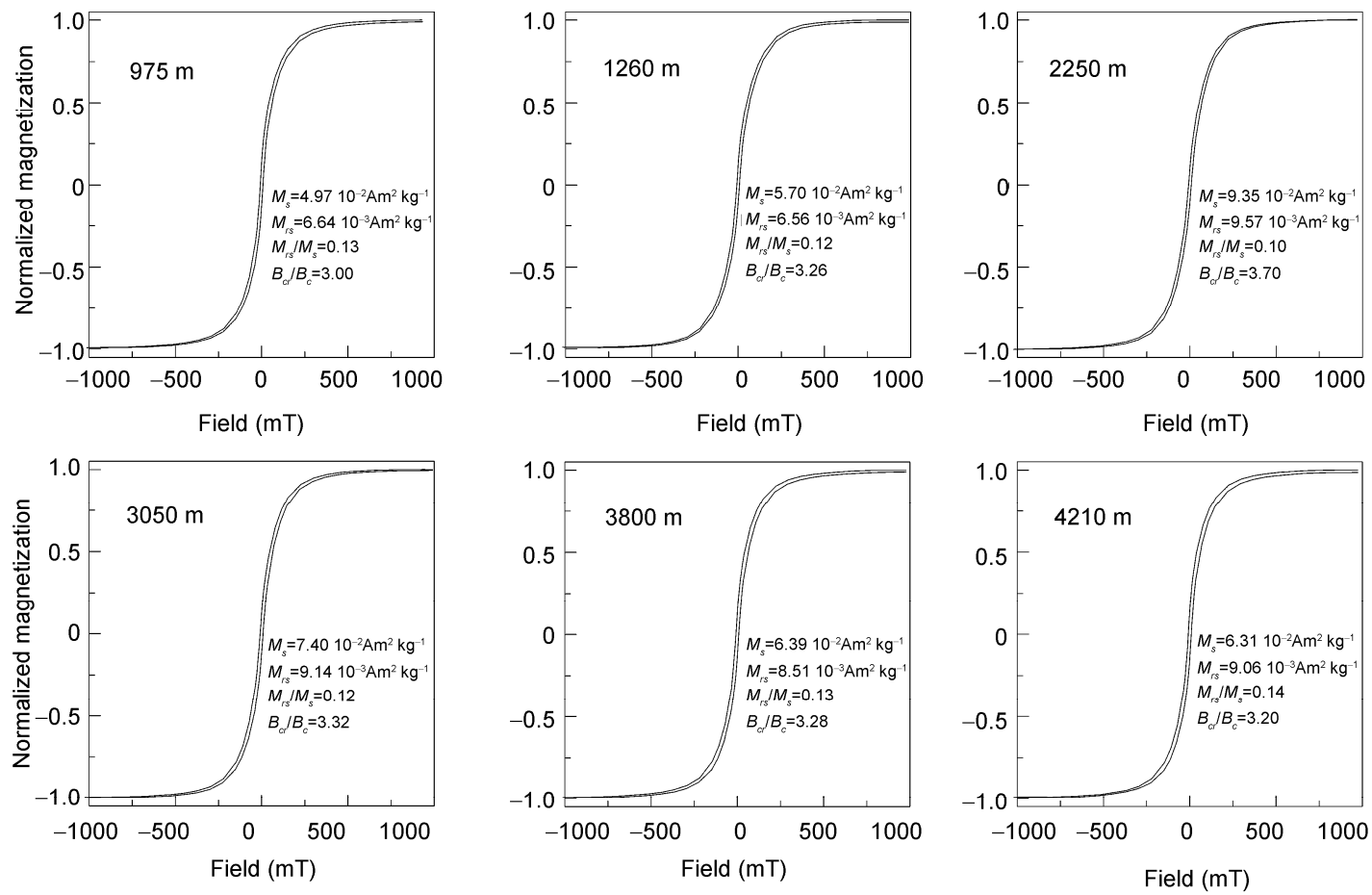

Figure 5 Hysteresis loops for surface aeolian sediments across the southern Tarim Basin (after slope correction for the paramagnetic contribution).
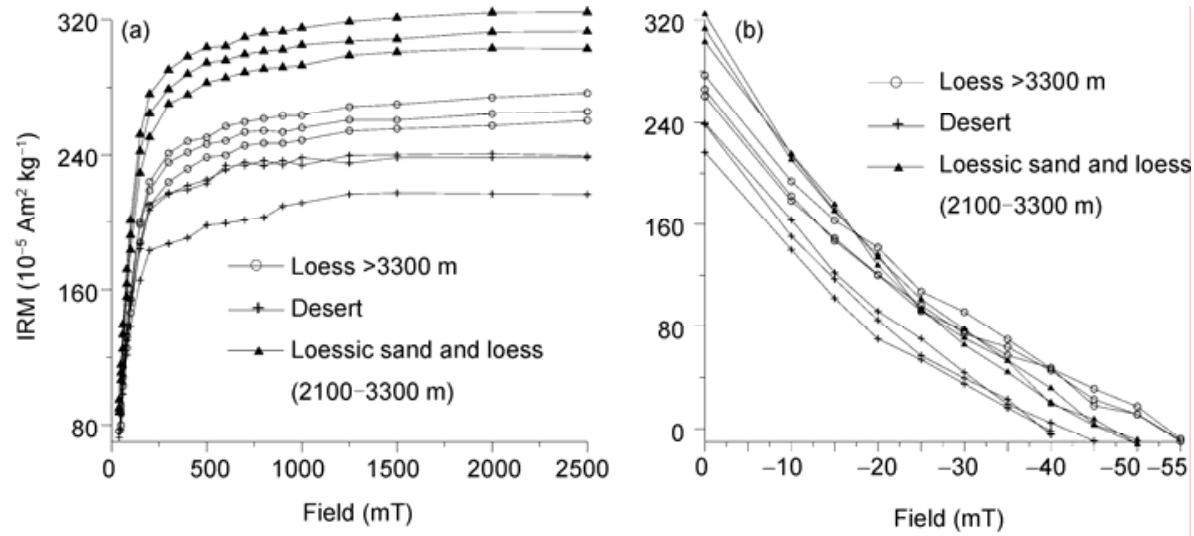

Figure 6 SIRM acquisition curves (a) and their reverse-field demagnetized curves (b) for surface aeolian sediments across the southern Tarim Basin.

\section{Discussion}

Our results suggest that samples taken from the desert have the lowest $\chi$ and that $\chi$ of loessic sand and loess samples decreases with increasing altitude. In general, the variations in aeolian facies belts and altitude accompany not only changes in rainfall and temperature conditions but also changes in the composition of aeolian dust due to wind sorting. Therefore, the magnetic properties of surface soils may vary across the southern Tarim Basin. However, it is worth emphasizing that soil provenance and the surface wind field can also affect $\chi$. Examining major-elemental and isotopic features in whole-rock samples, previous studies have found that there is strong homogenization of the sands across the entire Taklimakan Desert [28,29]. In addition, the strong aeolian activity in the Tarim Basin readily mixes aeolian sediments above $2100 \mathrm{~m}$. Thus, we argue that soil provenance and the surface wind field hardly affect the magnetic properties of surface soils across the southern Tarim Basin.

\subsection{Desert samples}

Rock magnetism studies suggest that although the magnetic properties of samples from Taklimakan Desert are dominated by soft magnetic minerals (i.e. magnetite), all samples have low values of $\chi$ and SIRM, implying the absolute concentration of magnetite is very low. In addition, in contrast to 
the good positive correlation between grain size and $\chi$ or SIRM in the case of surface sediments of loessic sands and loess (Figure 2), $\chi$ and SIRM of desert samples do not increase with increasing grain size. This indicates that the soft magnetic minerals, which dominate the magnetic properties of the surface soils across the southern Tarim Basin, are possibly concentrated in a specific grain-size range.

Previous rock magnetism studies of loess at the northeastern margin of the CLP based on Stokes' Law have found that wind sorting has a significant effect on the composition of magnetic minerals [22]. The magnetic properties of loess in that area are mainly controlled by the concentration of coarse aeolian magnetite $(31-90 \mu \mathrm{m})$. To further assess the relationship between grain size and the magnetic properties of surface sediments across the southern Tarim Basin, we show the correlation between the coarse grain population $(31-90 \mu \mathrm{m})$ and altitude, $\chi$ and SIRM in Figure 7. In contrast to the weak correlation between several grain size parameters and $\chi$ (Figure 8 ), the coarse grain population $(31-90 \mu \mathrm{m})$ and $\chi$ have a similar trend with increasing altitude (Figures 7(a) and 3(b)) and there is strong correlation between the coarse grain population $(31-90 \mu \mathrm{m})$ and $\chi$ or SIRM (Figure 7(b), (c)). As expected, this indicates that the magnetic properties of surface soils across the southern Tarim Basin are mainly controlled by the concentration of coarse aeolian ferrimagnetic minerals $(31-90 \mu \mathrm{m})$. However, we note that there are differences between grain size results obtained employing the two methods of laser granulometry and Stokes' Law [30] and emphasize that more detailed rock magnetism studies are needed.

\subsection{Loessic sand and loess samples}

In contrast to the weak correlation between $\chi$ and $\chi_{\mathrm{fd}}$ or $\chi_{\mathrm{fd}} \%$ (Figure 2), there is strong correlation between the coarse grain population $(31-90 \mu \mathrm{m})$ and $\chi$ or SIRM (Figure 7(b), (c)). These observations indicate that $\chi$ of loessic sand and loess are not determined by the concentration of pedogenic ultrafine magnetite/maghemite grains but by the concentration of coarse aeolian ferrimagnetic minerals.

However, rock magnetism studies indicate that climate conditions may have also affected $\chi$ of surface loess samples above $3300 \mathrm{~m}$. Thermomagnetic plots show that magnetization in the cooling curve for surface loess samples above $3300 \mathrm{~m}$ is much greater (more than double) than that in the heating curve and all heating curves have a clear "hump" at around $500^{\circ} \mathrm{C}$. Because these notable differences in mineralogy cannot be explained by the variation in grain size alone [19,20], these observations possibly imply that climate conditions (i.e. temperature and moisture) may have reached a threshold at about $3300 \mathrm{~m}$ and some of the magnetic mineral changed under the new condition $[19,20]$. According to meteorological records [24], the rate of increase in the mean annual precipitation with altitude for the
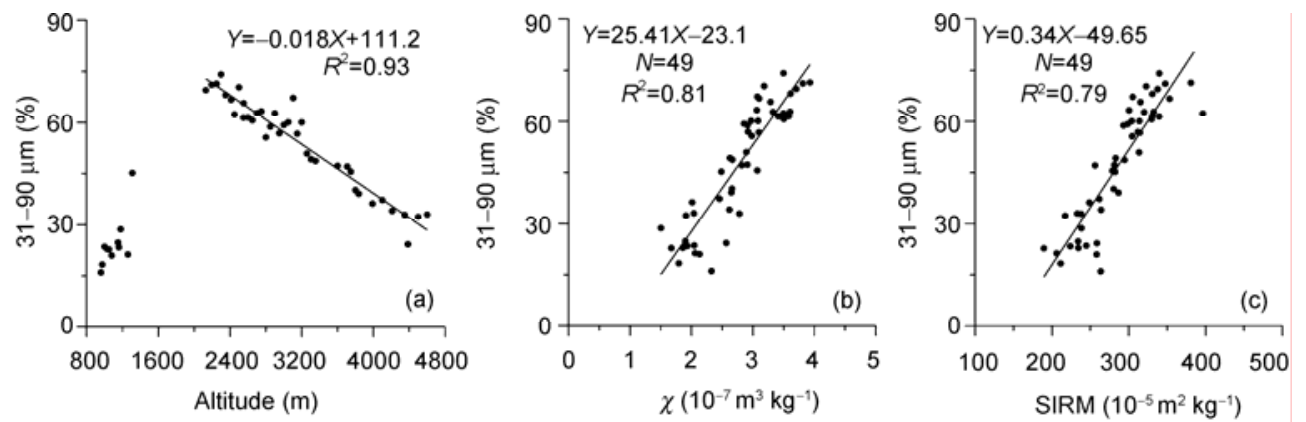

Figure 7 Relationships between the percentage content of 31-90 $\mu \mathrm{m}$ grains and altitude (a), $\chi$ (b) and SIRM (c) for surface aeolian sediments across the southern Tarim Basin.
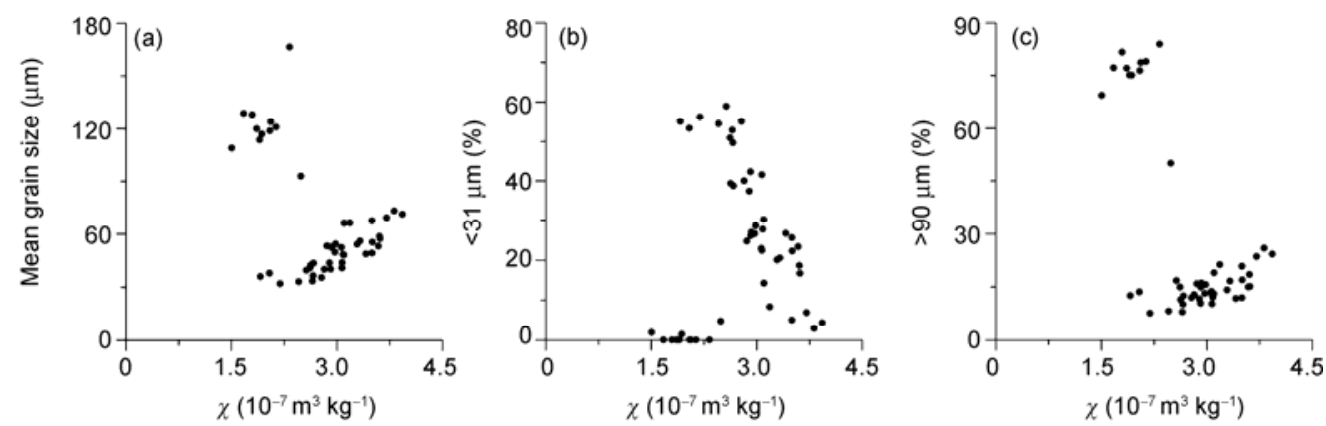

Figure 8 Relationships between (a) mean grain size and $\chi$, (b) percentage content of grains smaller than $31 \mu \mathrm{m}$ and $\chi$ and (c) percentage content of grains larger than $90 \mu \mathrm{m}$ and $\chi$ for surface aeolian sediments across the southern Tarim Basin. 
Kunlun Mountains is $18 \mathrm{~mm} / 100 \mathrm{~m}$ above $2000 \mathrm{~m}$ and the mean annual precipitation increases from $20-50 \mathrm{~mm}$ below $1500 \mathrm{~m}$ to more than $400 \mathrm{~mm}$ above $3500 \mathrm{~m}$. Considering the significant decrease in evaporation with increasing altitude, we believe that the humidity is sufficient for mineral transformation. However, our research is preliminary and we emphasize that more detailed rock magnetism studies are needed.

In summary, the above evidence suggests that the magnetic properties of surface soils across the southern Tarim Basin are mainly controlled by the concentration of coarse aeolian ferrimagnetic minerals. The contribution of ultrafine pedogenically produced magnetic grains is very limited. Thus, there is no obvious correlation between $\chi$ and the mean annual temperature or mean annual precipitation for surface soils across the southern Tarim Basin [9].

\section{Conclusion}

Our results suggest that samples taken from desert have the lowest $\chi$ values and that $\chi$ of loessic sand and loess samples decrease with increasing altitude. Ultrafine pedogenically produced magnetic grains make a very limited contribution to $\chi$ and the concentration of coarse aeolian ferrimagnetic minerals controls the magnetic properties of surface samples across the southern Tarim Basin.

This work was supported by the Knowledge Innovation Program of the Chinese Academy of Sciences (KZCXZ2-YW-Q09-04) and the National Natural Science Foundation of China (40972122, 40402017 and 40920114001).

1 Zhou L P, Oldfield F, Wintle A G, et al. Partly pedogenic origin of magnetic variations in Chinese loess. Nature, 1990, 346: 737-739

2 Maher B A, Thompson R. Mineral magnetic record of the Chinese loess and paleosol. Geology, 1991, 19: 3-6

3 Liu Q S, Banerjee S K, Jackson M, et al. Grain sizes of susceptibility and anhysteretic remanent magnetization carriers in Chinese loesspaleosol sequences. J Geophys Res, 2004, 109: B03101, doi: 10.10s29/2003JB002747

4 Liu Q S, Jackson M, Banerjee S K, et al. Mechanism of the magnetic susceptibility enhancements of the Chinese loess. J Geophys Res, 2004, 109: B12107, doi: 10.1029/ 2004JB003249

5 Deng C L, Liu Q S, Pan Y X, et al. Environmental magnetism of Chinese loess-paleosol sequences (in Chinese). Quat Sci, 2007, 27: 193-209

6 Liu Q S, Deng C L, Torrent J, et al. Review of recent development in mineral magnetism of the Chinese loess. Quat Sci Rev, 2007, 26: 368-385

7 Nie J S, King J W, Fang X M. Enhancement mechanisms of magnetic susceptibility in the Chinese red-clay sequence. Geophys Res Lett, 2007, 34: 19705, doi:10.1029/2007GL031430

8 Nie J, Song Y, King J, et al. Consistent grain size distribution of pedogenic maghemite of surface soils and Miocene loessic soils on the Chinese Loess Plateau. J Quat Sci, 2010, 25, 261-266

9 Lü H Y, Han J M, Wu N Q, et al. Magnetic susceptibility of Chinese modern soils and its palaeoclimatic significance (in Chinese). Sci
China Ser B, 1994, 24: 1290-1297

10 Maher B A, Thompson R. Paleorainfall reconstructions from pedogenic magnetic susceptibility variations in the Chinese loess and paleosols. Quat Res, 1995, 44: 383-391

11 Maher B A. Magnetic properties of modern soils and Quaternary loessic paleosols: Paleoclimatic implications. Palaeogeogr Palaeoclimatol Palaeoecol, 1998, 137: 25-54

12 Florindo F, Zhu R X, Guo B. Low-field susceptibility and palaeorainfall estimates: new data along a N-S transect of the Chinese Loess Plateau. Phys Chem Earth (A), 1999, 24: 817-821

13 Evans M E, Rokosh C D, Rutter N W. Magnetoclimatology and paleoprecipitation: evidence from a north-south transect through the Chinese Loess Plateau. Geophys Res Lett, 2002, 29: 1285, doi: 10. 1029/2001GL013674

14 Bloemendal J, Liu X M. Rock magnetism and geochemistry of two Plio-Pleistocene Chinese loess-palaeosol sequences-implications for quantitative palaeoprecipitation reconstruction. Palaeogeogr Palaeoclimatol Palaeoecol, 2005, 226: 149-166

15 Begét J E, Stone D B, Hawkins D B. Paleoclimatic forcing of magnetic susceptibility variations in Alaska loess during the late Quaternary. Geology, 1990, 18: 40-43

16 Chlachula J, Evans M E, Rutter N. A magnetic investigation of a late Quaternary loess/palaeosol record in Siberia. Geophys J Int, 1998, 132: 128-132

17 Zhu R X, Alexey K, Galina M, et al. Rock-magnetic investigation of Siberia loess and its implication. Chinese Sci Bull, 2000, 45: 21922198

18 Zhu R X, Matasova G, Kazansky A, et al. Rock magnetic record of the last glacial-interglacial cycle from the Kurtak loess section, southern Siberia. Geophys J Int, 2003, 152: 335-343

19 Liu X M, Hesse P, Rolph T, et al. Properties of magnetic mineralogy of Alaskan loess: Evidence for pedogenesis. Quat Int, 1999, 62: 92-102

20 Liu X M, Liu T S, Paul Hesse, et al. Two pedogenic models for paleoclimatic records of magnetic susceptibility from Chinese and Siberian loess. Sci China Ser D, 2008, 51: 284-293

21 Wang Y, Pan B T, Guan Q Y, et al. Magnetic susceptibility variation in semiarid region of northwestern China (in Chinese). Mar Geol Quat Geol, 2008, 28: 111-114

22 Sun J M, Liu T S. Multiple origins and interpretations of the magnetic susceptibility signal in Chinese wind-blown sediments. Earth Planet Sci Lett, 2000, 180: 287-296

23 Yang X P. The grain size of the windborne sediments in the areas of Keriya River (northwestern china) and its paleoenvironmental interpretation (in Chinese). Quat Sci, 1999, 4: 373-379

24 Li J F. Xinjiang Climate (in Chinese). Beijing: China Meteorological Press, 1991. 97-124

25 Thompson R, Oldfield F. Environmental Magnetism. London: Allen and Unwin, 1986. 1-227

26 Evans M E, Heller F. Environmental Magnetism: Principles and Applications of Enviromagnetics. New York: Academic Press, 2003. $1-322$

27 Dankers P. Relationship between median destructive field and remanent coercive force for dispersed natural magnetite, titanomagnetite and hematite. Geophys J Res, 1981, 64: 447-461

28 Hattori Y, Suzuki K, Honda M, et al. Re-Os systematics of the Taklimakan Desert sands, moraines and river sediments around the Taklimakan Desert, and of Tibetan soils. Geochim Cosmochim Ac, 2003, 67: 1195-1205

29 Honda M, Shimizu H. Geochemical, mineralogical and sedimentological studies on the Taklimakan Desert sands. Sedimentology, 1998, 45: 1125-1143

30 Hao Q Z, Oldfield F, Bloemendal J, et al. Particle size separation and evidence for pedogenesis in samples from the Chinese Loess Plateau spanning the last $22 \mathrm{Ma}$. Geology, 2008, 36: 727-730

Open Access This article is distributed under the terms of the Creative Commons Attribution License which permits any use, distribution, and reproduction in any medium, provided the original author(s) and source are credited. 